\title{
Improved Water Management for PEFC with Interdigitated Flow Fields using Modified Gas Diffusion Layers
}

\author{
Victoria Manzi-Orezzoli, ${ }^{1}$ Muriel Siegwart, ${ }^{1,2}$ Magali Cochet, ${ }^{1}$ Thomas J. Schmidt, ${ }^{1,3, *}$ \\ and Pierre Boillat $\oplus^{1,2, * *, z}$
}

\author{
${ }^{1}$ Electrochemistry Laboratory, Paul Scherrer Institute, CH-5232 Villigen, Switzerland \\ ${ }^{2}$ Laboratory for Neutron Scattering and Imaging, Paul Scherrer Institute, CH-5232 Villigen, Switzerland \\ ${ }^{3}$ Laboratory of Physical Chemistry, Department of Chemistry \& Applied Biosciences, ETH Zürich, CH-8093 Zürich, \\ Switzerland
}

\begin{abstract}
Polymer electrolyte fuel cells (PEFCs) with interdigitated flow fields were operated with modified gas diffusion layers (GDLs). Interdigitated flow fields have dead-ended channels, which forces the gas to flow convectively through the GDLs to the outlet channels and significantly reduces the mass transport losses. However, when using conventional GDLs, the water accumulation at the end of the inlet channels results in an increased and unpredictable pressure drop, which translates in unstable performance. This has prevented so far the use of this kind of flow fields in a stack configuration. Here, we show how GDLs optimized for water management with designed hydrophilic lines facilitate the transport of water from the dead ends to the outlet channels, which results in a lower and predictable pressure drop and in a stable performance. The voltage and pressure drop measurements were complemented by liquid water distribution measurements using high resolution neutron imaging to elucidate the water transport mechanisms. The stable pressure drop obtained with our customized GDLs allows to expect this configuration to be suitable for stack operation, opening the way to bring the benefits of interdigitated flows fields - high power density with low mass transport losses - to real fuel cell systems. (C) The Author(s) 2019. Published by ECS. This is an open access article distributed under the terms of the Creative Commons Attribution Non-Commercial No Derivatives 4.0 License (CC BY-NC-ND, http://creativecommons.org/licenses/by-nc-nd/4.0/), which permits non-commercial reuse, distribution, and reproduction in any medium, provided the original work is not changed in any way and is properly cited. For permission for commercial reuse, please email: oa@electrochem.org. [DOI: 10.1149/2.0062005JES]
\end{abstract}

(cc) BY-NC-ND

Manuscript submitted July 25, 2019; revised manuscript received October 11, 2019. Published November 26, 2019. This was Paper 1485 presented at the Atlanta, Georgia, Meeting of the Society, October 13-17, 2019. This paper is part of the JES Focus Issue on Heterogeneous Functional Materials for Energy Conversion and Storage.

Polymer electrolyte fuel cells (PEFCs) are a promising technology to help in the energy transition from fossil-based technologies toward sustainable energy systems. Fuel cell vehicles are already commercially available but the technology could benefit from higher performing fuel cell stacks, where a well-balanced water management and reduction of mass transport losses are key concepts.

A conventional PEFC uses parallel flow field designs where the reactant gases are supplied through the continuous channels and diffuse through a porous media to the catalyst layers (Figure 1a). Hydrogen is oxidized at the anode side and protons are conducted through the polymer electrolyte membrane to the cathode side, where oxygen is reduced and reacts with protons to form water. This water is transported in gaseous or liquid form to the flow field channels, through the same porous media used for the supply of reactants. This porous media, generally known as gas diffusion layer (GDL), acts as gas distributor, heat and electron conductor and is the most important component for water managment. ${ }^{1}$ PEFCs require sufficient water in the membrane to ensure its ionic conductivity but an excess of liquid water hinders the access of the reactants to the catalyst, which results in performance losses, known as mass transport losses. Keeping this balance is what is understood as a good water management of the cell, and is particularly important in the cathode. Due to the slow kinetics of the oxygen reduction reaction and the fact that the transport of reactant through the GDL is based on diffusion, the reaction is subjected to significant mass transport losses, especially at high current densities. ${ }^{2-6}$

One way to limit these losses is to use an interdigitated flow field. With this design, the inlet channels are dead-ended and the only way for gases to leave the cell is by flowing under the rib, through the gas diffusion layers to the outlet channels (Figure 1b). This technology was originally published by Nguyen ${ }^{7}$ and has demonstrated that it can improve cell performance since the gas transport by convection maximize the concentration gradient in the GDL which improves the transport occurring by diffusion. Tajiri et al. ${ }^{3}$ used a fuel cell with interdigitated flow field in the cathode and a segmented cell flow field

\footnotetext{
*Electrochemical Society Fellow.

***Electrochemical Society Member

${ }^{\mathrm{z}}$ E-mail: pierre.boillat@psi.ch
}

in the anode to analyze the oxygen transport in the cell and compared it to a conventional flow field by studying the limiting current density and its distribution through the cell. They calculated that the use of interdigitated flow fields promotes a convective transport through the GDL under the lands of the flow field. According to them, the convective flow is not homogeneously distributed over the GDL thickness but predominantly occurs in the portion of the GDL that is near the flow field, and the transport through the remaining GDL thickness still relies on diffusion. However, the diffusion path length is significantly shortened by the use of interdigitation, which strongly decreases the
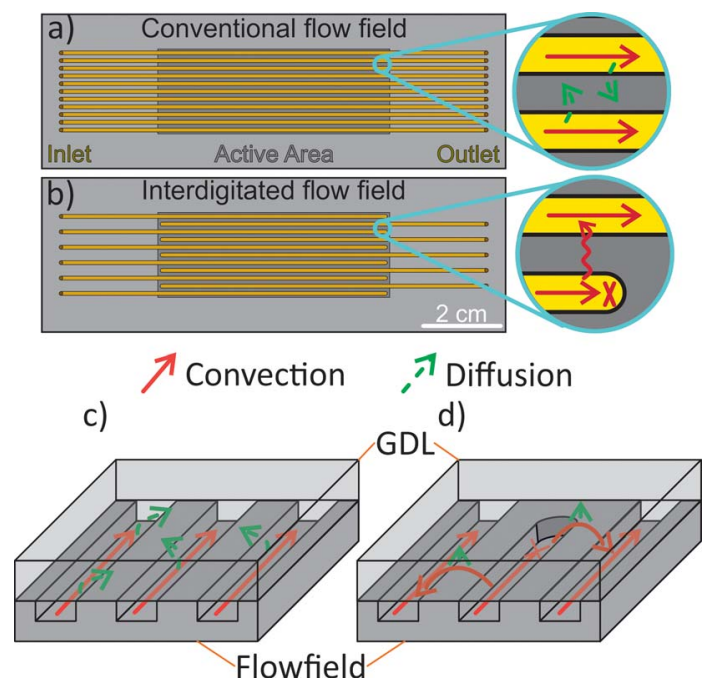

Figure 1. Sketch of a) a conventional parallel flow field and b) an interdigitated flow fields. c) In a conventional parallel flow fields gas transport along the channels occurs by convection meanwhile gas transport through the GDL occurs by diffusion. d) The gas transport along the channels of an interdigitated flow field also happens by convection but the dead ended channels force part of the gas transport through the GDL to occur by convection, diminishing the diffusion path length. 
mass transport losses in comparison to conventional flow fields. Nevertheless, at higher current densities this effect is limited due to water accumulation in the dead ended sections of the inlet channels and in the GDL.

The forced gas flow through the GDL due to the interdigitated channels generates a pressure drop between inlet and outlet, $\Delta \mathrm{P}$, which is related to the permeability of the GDL. $\Delta \mathrm{P}$ depends on the flow field design and on the characteristics of the GDL, but is also highly dependent on the water content in the GDL and the gas channels. When the gas channels are partially filled with water, the length of the GDL the gas has to cross in order to get to the outlet channel is larger and the pressure drop increases. Also, when the end of the channels are filled with water, the effectively used length of the channel decreases and the convective flow is forced through a smaller section of the GDL. Since the gas flow stays constant, the velocity of the convective flow in the GDL increases, resulting in a rise of the pressure drop. Additionally, a GDL with a high water content has a decreased gas permeability, which further increases the pressure drop. This relation makes interdigitated flow fields interesting to be used as an analytical tool to quantify the amount of water in the cell. ${ }^{8-10}$ However, this same property is what limits the application of interdigitated flow fields for fuel cell stacks.

Water management is a major issue for interdigitated flowfields. Water accumulation can happen even at a comparatively low relative humidity of the inlet gas flow, as the contribution of electrochemically produced water and drag water from the anode side can increase the relative humidity in the inlet regions of the flow field until condensation occurs. Due to the capillary pressure barrier imposed by the hydrophobic GDL, water accumulates at the end of the inlet channels, which leads to high and unpredictable pressure drops that translate in unstable cell performance. ${ }^{11}$ Cooper et al. ${ }^{12}$ reached the same conclusion by comparing different channel length in interdigitated flow fields. They used a unique flow field with different outlets which could selectively be closed to change the channel length. They compared performance, pressure drop and water accumulation from three different channel lengths, depicting that shorter channels results in better performance. Their studies included a comparison of water content obtained from neutron imaging and pressure drop values from experimental tests and simulations. They highlighted that, even if the forced convection is less effective in longer channels, the main difference in performance comes from water accumulation at the end of the inlet channels, since longer channels accumulated more water. Their conclusion is that a water elimination system will be necessary for the use of interdigitated flow field in cells of technical size.

In our research group, a technique was developed to allows the creation of hydrophilic pathways by altering the chemical composition of the GDL's fluoropolymer coating. ${ }^{13}$ This modification has proven to improve performance, and the analysis of water distribution by neutron imaging showed that water accumulates in the hydrophilic lines of the material, specifically under the rib regions of the flow field, and is then distributed to the channels. ${ }^{14}$

Here, we propose to combine an interdigitated flow field with this modified GDL with hydrophilic water pathways. The patterned GDL creates a water by-pass, lowering the required capillary pressure for the water to be transported from the inlet to the outlet channels, which helps to avoid water accumulation, decreases the cell's pressure drop and increases performance stability.

\section{Experimental}

Patterned GDL.-The general concept of the GDL modification procedure has been previously reported, ${ }^{13}$ and is summarized here for the sake of clarity. The GDLs are coated using a fluoropolymer to enhance hydrophobicity. Then, the coated GDL is irradiated with electrons with masks over the sample. The mask has defined openings that let the electron beam pass through with the rest of the beam being blocked. The electrons generate radicals on the coating acting as initiators for radical polymerization with a second polymer changing the wettability only in the activated regions.
For this experiment, a carbon paper (Freudenberg H23) was used as a base GDL material. The GDL was coated in-house with $30 \%$ FEP, followed by application of a microporous layer (MPL). The MPL ink was obtained by mixing $116 \mathrm{mg}$ of carbon (Acetylene Black, $50 \%$ compressed, Alfa Aesar) with $70 \mathrm{mg}$ of fluoropolymer dispersion (FEP $55 \%$, FEPD 121 DuPont) and a solvent solution. This solvent was prepared by mixing $11 \mathrm{~mL}$ of Isopropanol (Sigma Aldrich) and $7.4 \mathrm{~mL}$ of ultrapure water with a magnetic stirrer for 5 minutes. The solvent solution was first poured over the fluoropolymer dispersion and stirred for another 5 minutes. The resulting was then slowly added to the carbon particles while manually stirring. Then the ink was sonicated for an hour. $0.33 \mathrm{~mL} / \mathrm{cm}^{2}$ of this ink was applied on the GDL by spraying. The samples were then heated at $280^{\circ} \mathrm{C}$ following the temperature program reported in a previous publication, ${ }^{15}$ in order to sinter the fluoropolymer particles from the GDL coating and from the MPL.

The material was modified using a pattern of alternating $500 \mu \mathrm{m}$ wide hydrophilic lines separated by $940 \mu \mathrm{m}$ wide hydrophobic line, repeated along the entire GDL. The wettability of each region was characterized by the intrinsic contact angle, which was evaluated to be $30^{\circ}$ for the hydrophilic region and $110^{\circ}$ for the hydrophobic region, based on measurements done on flat films. ${ }^{13}$ To achieve this modification, the samples were irradiated using an electron beam (EBLab 200 sealed laboratory emitter system, Comet AG, Switzerland) with an energy of $140 \mathrm{keV}$ and $50 \mathrm{kGy}$ dose. The energy was chosen to selectively graft the GDL layer without modifying the MPL. After activation, the GDLs were immersed in pure $\mathrm{N}$-vinylformamide (SigmaAldrich). After bubbling $\mathrm{N}_{2}$ for an hour into the reactor to prevent the presence of $\mathrm{O}_{2}$, the reactor was sealed and placed in a water bath at $70^{\circ} \mathrm{C}$ for an hour. The samples were then cleaned under vacuum first with ethanol, then with isopropanol and finally with ultrapure water before the samples were dried in a vacuum oven. This technique was selected due to its ability of modify the coating surfaces of the entire GDL through its entire thickness (with the exception of the MPL layer, as explained above).

Fuel cell test.-The used cell fixture was identical as the one described in a previous publication, ${ }^{16}$ but with different flow fields. It included pressure sensors attached to each inlet and outlet in order to measure the pressure drop. The cell had a $11.6 \mathrm{~cm}^{2}$ active area ( $20 \mathrm{~mm}$ wide and $58 \mathrm{~mm}$ long) and was built with an asymmetric flow field configuration using an aluminum gold coated parallel flow field (Figure 1a) for the anode and a stainless steel gold coated interdigitated flow field for the cathode (Figure 1b). To be able to assess the effectiveness of the modified material for water management, only the type of GDL used for the cathode was varied between the two cells. For both cell assemblies, the anode GDL was a Freudenberg H23 C6 with a total thickness of $250 \mu \mathrm{m}$. The catalyst coated membrane (CCM) of type Primea 5710 (W.L. Gore \& Associates, with platinum loadings of $0.1 \mathrm{mg}_{\mathrm{Pt}} / \mathrm{cm}^{2}$ on the anode and $0.4 \mathrm{mg}_{\mathrm{Pt}} / \mathrm{cm}^{2}$ on the cathode) and the GDLs where hot pressed at $140^{\circ} \mathrm{C}$ under $3 \mathrm{~N} / \mathrm{m}^{2}$ for 2 minutes prior to mounting. The cell labelled as commercial included a Freudenberg H23 C6 GDL as the cathode GDL and the one labelled as patterned included the in-house modified GDL with patterned wettability described above as the cathode GDL, with the hydrophilic/hydrophobic lines perpendicular to the flow channels. All GDLs were compressed to $70 \%$ of their original thickness in the final cell assembly.

All test were performed at a temperature of $70^{\circ} \mathrm{C}$ and outlet pressures of 2 bar $_{\text {abs }}$, (fixed with a downstream pressure controller) with a relative humidity of $75 \%$ at the anode inlet and $50 \%$ at the cathode inlet. The anode stoichiometry was fixed for all test at 2.5. The cells were operated in counter flow configuration.

The cell high frequency resistance (HFR), was constantly monitored by applying a sinusoidal current perturbation with a frequency of $4793 \mathrm{~Hz}$, and measuring the corresponding voltage response.

Two different protocols were used to test the cells: polarization curves (IV curves) were acquired using 10 potential steps, where each current was hold for 15 minutes and the average of the last minute of each step was used as measurement point. The IV curves were 


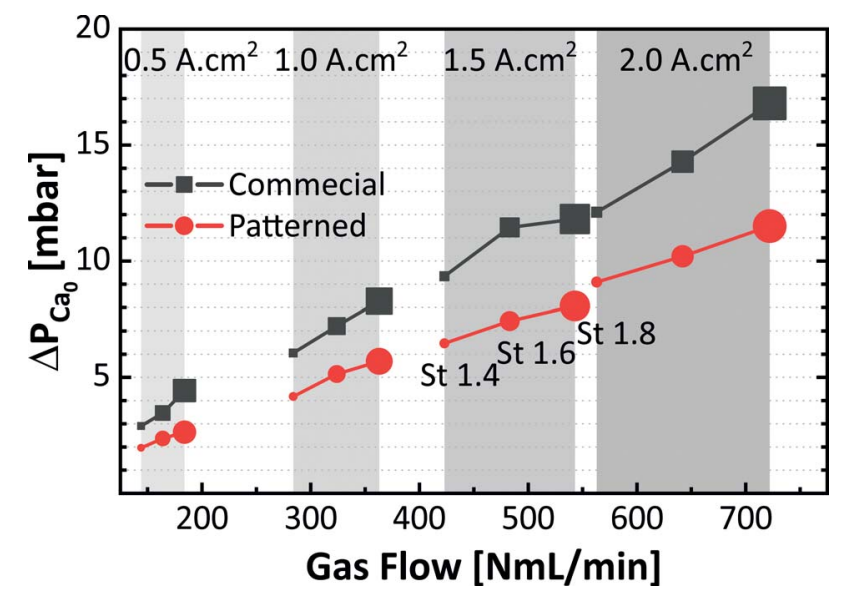

Figure 2. Initial pressure drop for every gas flow depending on the test conditions. The gray squares represent the commercial GDL and red circles the patterned GDL. Large symbol corresponds to flow used for a cathode stoichiometry of 1.8 , middle for 1.6 and small 1.4. The gray zones correlate the current density with the gas flow.

acquired using fixed stoichiometries of 2.5 for the anode and 1.6 for the cathode.

The second test protocol consisted in the following steps: four different current densities $\left(0.5,1.0,1.5,2.0 \mathrm{~A} / \mathrm{cm}^{2}\right)$ were held each for 1 hour for three values of cathode stoichiometry (1.4, 1.6 and 1.8). Before every current step, the cell was purged using symmetric flows of $750 \mathrm{NmL} / \mathrm{min} \mathrm{H}_{2} / \mathrm{N}_{2}$ and $30 \%$ relative humidity at both inlets for 10 minutes, followed by 5 minutes conditioning. During conditioning, no current was drawn but the gas type, gas flow and R.H. was the same as for following measurement point (the gas flows were adjusted for each stoichiometry and current step).

The pressure drop on the cathode $\left(\Delta \mathrm{P}_{\mathrm{Ca}}\right)$ is defined as

$$
\Delta P_{C a}=P_{C a \text { inlet }}-P_{C a \text { outlet }}
$$

The mean value of $\Delta \mathrm{P}_{\mathrm{Ca}}$ measured during the last minute of the conditioning step is taken as the reference for the cathode pressure drop $\left(\Delta \mathrm{P}_{\mathrm{Ca} 0}\right)$ in absence of liquid water. The increase of pressure drop due to water accumulation, $\Delta \mathrm{P}_{\mathrm{Ca}}^{\mathrm{r}}$, is calculated by subtracting $\Delta \mathrm{P}_{\mathrm{Ca} 0}$ from the pressure drop measured during the experiment. The comparison of pressure drop increase instead of the absolute pressure drops allows to highlight the differences in pressure drop generated by the water accumulation because it minimized the effect that employing different gas flows have in the measurement and the effect of the intrinsic differences between the two used GDLs. A summary of all the measured values of $\Delta \mathrm{P}_{\mathrm{Ca} 0}$ can be found in Figure 2. The pressure drop increases linearly with the gas flow. As expected, higher stoichiometries result in higher $\Delta \mathrm{P}_{\mathrm{Ca} 0}$ and the observed deviations from linearity (including the higher point for the gas flow required for a 1.6 stoichiometry at $1.5 \mathrm{~A} / \mathrm{cm}^{2}$ ) are within the experimental error. However, the commercial GDL shows a higher $\Delta \mathrm{P}_{\mathrm{Ca} 0}$ than the modified one. We attribute these differences to coating distribution, but also to possible differences in the MPL configuration, i.e. a lower penetration of the MPL into the GDL for the patterned sample in comparison to the commercial sample.

Neutron imaging setup.-The neutron radiography experiments were performed at the NEUTRA beamline of the Swiss Spallation Source (SINQ) at PSI. ${ }^{17}$ A gadolinium sheet with $2 \mathrm{~mm}$ horizontal slits was used to increase the beam collimation in vertical direction to an $\mathrm{L} / \mathrm{D}$ ratio of 1750 in order to limit the blurring due to beam divergence. The anisotropic resolution enhancement method by detector tilting previously reported ${ }^{18}$ was used. The neutrons were captured using a $10 \mu \mathrm{m}$ scintillator screen made of $\mathrm{Gd}_{2} \mathrm{O}_{2} \mathrm{~S}$, tilted to form an angle of $10^{\circ}$ with the beam axis. The resulting light output image was collected through a set of 2 mirrors and a commercial optical lens (Zeiss Makro
Planar T100) by a CCD camera (Andor Ikon-L, $2048 \times 2048$ pix). The acquisition time was set to $30 \mathrm{~s}$ and images were acquired continuously during the measurements, with an acquisition rate of 2 images per minute.

Image processing.-Detailed information about the general methodology employed for image processing can be found elsewhere. ${ }^{19}$ In particular, for this experiment the images were corrected for outliers. Removing them by using a 3-dimensional filter size of $5 \times 5 \times 3$ on the measured time sequences. Subsequently, the images were corrected for spatial inhomogeneities of the neutron beam, displacement and for the background related to scattered neutrons ${ }^{20}$ and a Gaussian blur filter (sigma $=0.75$ pix) was applied to remove the noise in high spatial frequencies. Finally, the images were divided pixel-wise by an image of the dry cell to facilitate water quantification and averaged over a certain period of time, stated later in the text, to improve the signal-to-noise ratio.

The thickness of water was quantified using the Lambert-Beer law:

$$
\frac{I}{I_{\text {ref }}}=e^{-\Sigma x}
$$

where $I$ is the intensity of the beam after the sample, $I_{r e f}$ is the reference intensity - in our case, the intensity of the beam transmitted through the dry cell without operation,$- \Sigma$ is the water attenuation coefficient with a value of $0.35 \mathrm{~mm}^{-1}$ for the NEUTRA beam line and for the used detector configuration, and $x$ is the water thickness.

Due to the different materials used in the flow fields, the quantification of water is more challenging in the cathode channels. The anode flow field is made of aluminum, which has a low neutron cross section, and thus a high transmission. The cathode flow field is made of stainless steel that has a higher neutron cross section. Transmission through the dry flow field was low ( $9 \%$ of the open beam), because $19 \mathrm{~mm}$ of stainless steel were in the beam. When water is present in the flow field channels, transmission is even lower (as low as $1 \%$ compared to the open beam). When approaching zero transmission, even minimal errors in the scattered background evaluation can have an important impact. A cut off value of $10 \%$ for $I / I_{\text {ref }}$ was therefore set. If the transmission of the working image over the dry image was lower than $10 \%$, the value of the calculated water thickness was considered not to be reliable and shown in light gray. This threshold represents a thickness of $6.6 \mathrm{~mm}$ of water, above which the water can be detected but not quantified.

\section{Results and Discussion}

Performance measured by IV curves.-Figure 3 compares the $\Delta \mathrm{P}_{\mathrm{Ca}}$ (a) and IV curves (b) measured for the cells with patterned and commercial GDL at the cathode side. The cell with the commercial GDL reaches a much higher pressure drop and lower performance at high current densities (i) compared to cell with the patterned GDL. In this case, the initial pressure $\operatorname{drop}\left(\Delta \mathrm{P}_{\mathrm{Ca} 0}\right)$ is not subtracted from $\Delta \mathrm{P}_{\mathrm{Ca}}$ because there is no conditioning step to measure $\Delta \mathrm{P}_{\mathrm{Ca} 0}$. Therefore, the values shown are a combination of the pressure drop due to the increasing gas flows plus the effect of water accumulation in the GDL and channels. A linear increase of pressure drop is expected due to the use of different gas velocities for every current density, as can also be seen in Figure 2.

The pressure drop with the patterned wettability sample evolves linearly for most of the IV curve, which means that friction is constant, and that water accumulation is not disrupting the gas flow up until $\mathrm{i}=1.2 \mathrm{~A} / \mathrm{cm}^{2}$. On the other hand, with the commercial GDL, the pressure drop evolve non-linearly and increase much faster with gas flow rate, indicating that the water disturbs the gas path. Especially at high current densities $\left(\mathrm{i}=1.5 \mathrm{~A} / \mathrm{cm}^{2}\right)$, the pressure drop for the commercial sample is significantly higher and the performance of the commercial cell is about $140 \mathrm{mV}$ lower compared to the cell with the patterned sample. For the last tested current point, the performance of the commercial sample improves slightly, as well as the pressure drop decreases. This is a good example of the performance instability 


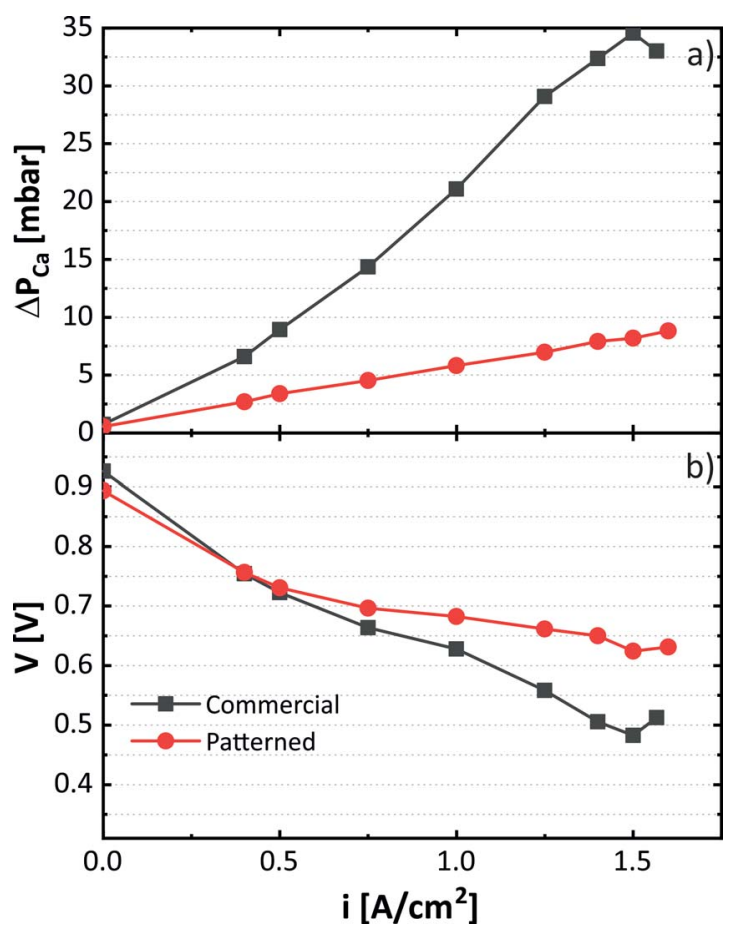

Figure 3. Performance analysis of two different cells: commercial GDL (gray squares) and patterned GDL (red circles). a) Pressure drop on the cathode, not referenced, vs current density. b) Polarization curve. Operating stoichiometries: $2.5_{\text {Anode }} / 1.6_{\text {Cathode }}$.

of cells operated with interdigitated flow fields without an improved water management system. On the other hand, the patterned sample shows a much lower pressure drop and a higher cell performance.
This is an indication that the patterned GDL helps - as expected to decrease the water accumulation in the channels and therefore the mass transport losses.

Stability during 1 hour of operation.-To be able to assess the efficiency of the patterned GDL for operation with the interdigitated flow field, the stability of the cell performance must be considered. We tested the materials by holding a given current for at least an hour while measuring the voltage $(\mathrm{V})$, the pressure drop increase $\left(\Delta \mathrm{P}_{\mathrm{Ca}}^{\mathrm{r}}\right)$ and the water distribution. For all the following experiments, the pressure drop increase due to water is presented instead of the absolute pressure drop, to exclude the influence of the change in gas flow at different current densities and stoichiometries.

Figures 4 and S1 show the results for one of the harshest conditions tested, a cathode stoichiometry of 1.4 and a current density of $1.5 \mathrm{~A} / \mathrm{cm}^{2}$. The lower gas flow is less efficient for water removal, and at the same time the operation at high current density cause higher water production. Both conditions favours water accumulation and makes it more difficult to achieve an adequate water management.

During the first 5 minutes of operation, the initial voltage of the cell with the commercial sample is significantly higher than the one for the cell with the patterned sample, but the pressure drop increase $\Delta \mathrm{P}_{\mathrm{Ca}}^{\mathrm{r}}$ is similar for both cells. After this initial period, the cell using the patterned sample shows a stable performance: $\mathrm{V}=0.61 \pm 0.01 \mathrm{~V}$ and $\Delta \mathrm{P}_{\mathrm{Ca}}^{\mathrm{r}}=10.5 \pm 1.2$ mbar. For the cell with the commercial sample, there is a gradual increase in pressure drop, which correlates to the gradual decrease in cell voltage. At minute 35 , a sharp increase of $\Delta \mathrm{P}_{\mathrm{Ca}}^{\mathrm{r}}$ to 29 mbars is observed, and the voltage drops abruptly. A safety voltage cutoff of $0.2 \mathrm{~V}$ was set to avoid to have a cell voltage reversal and damage the CCM. To be able to continue the experiment, no current was drawn for 5 minutes, allowing the cell to dry partially. This drying period was sufficient to operate the cell again but not to recover the initial state and, therefore, $\Delta \mathrm{P}_{\mathrm{Ca}}^{\mathrm{r}}$ is higher and the voltage lower than at the beginning of operation. At minute $68, \Delta \mathrm{P}_{\mathrm{Ca}}^{\mathrm{r}}$ starts to rise again concomitant with a voltage drop at minute 76 . For both tested cells the high frequency resistance (HFR) is stable (Figure S1), only

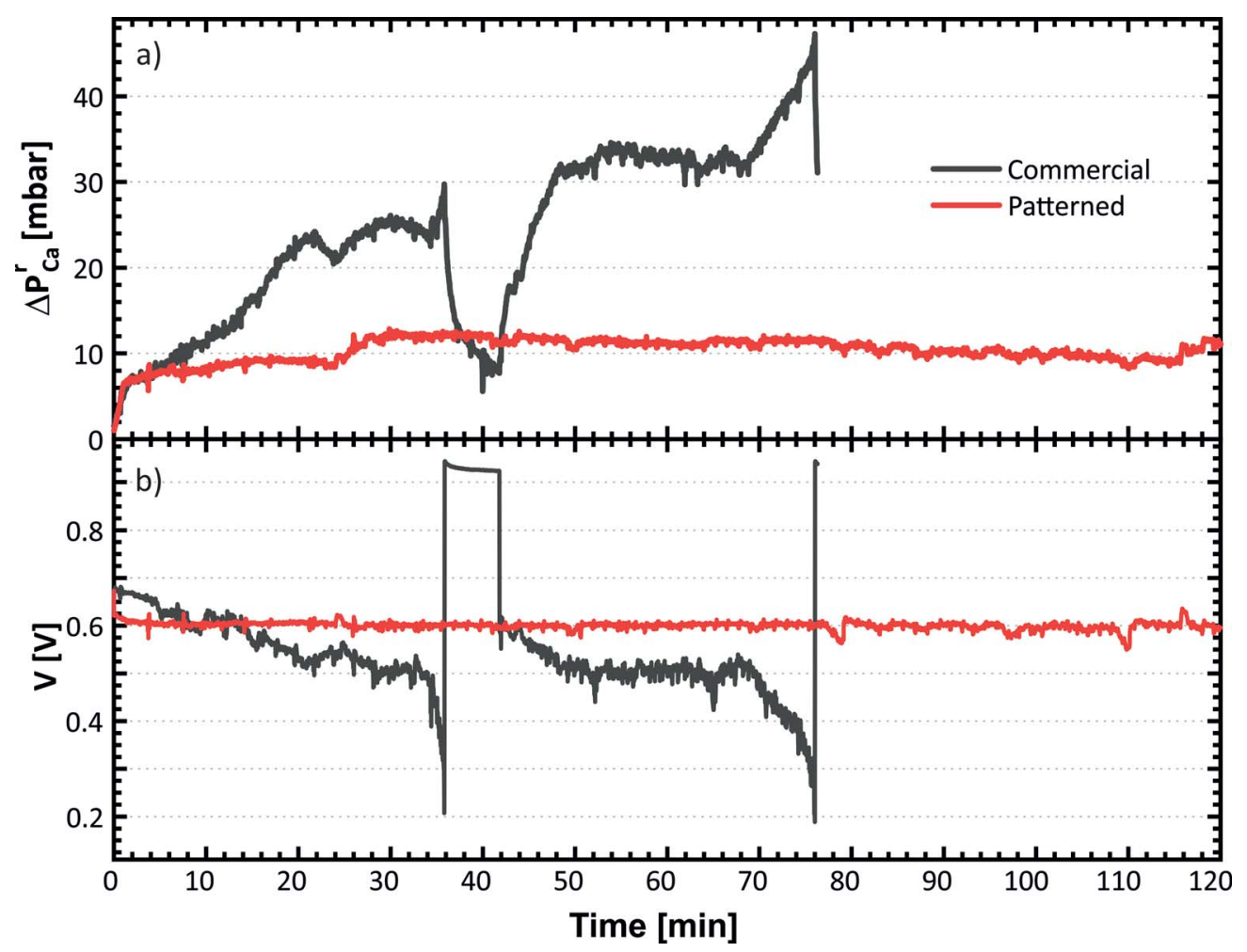

Figure 4. Performance of two different cells: commercial in gray, patterned in red. a) Cathode pressure drop vs time. b) Voltage vs time. Operating conditions: stoichiometry $1.4, i=1.5 \mathrm{~A} / \mathrm{cm}^{2}$. 

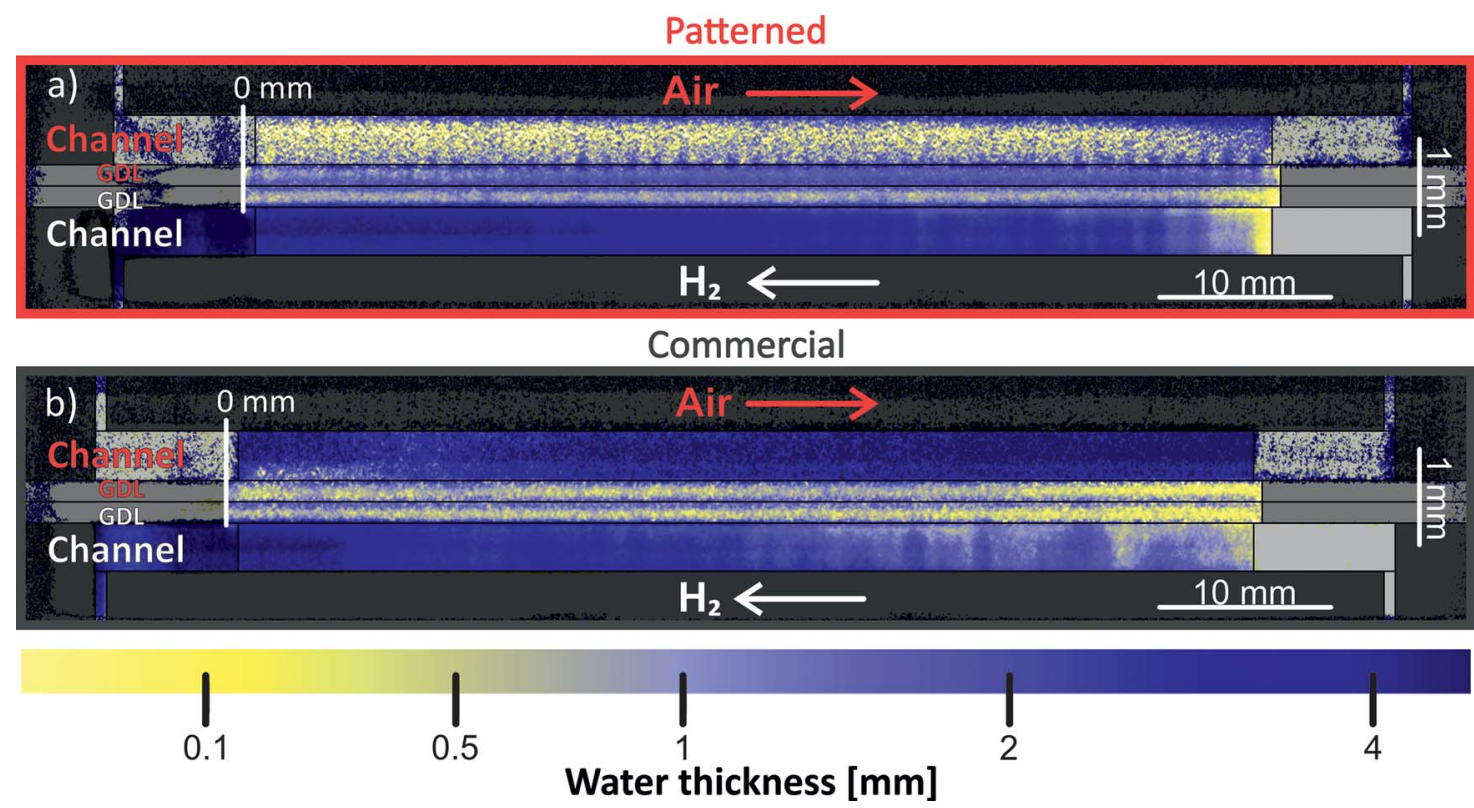

Figure 5. Neutron radiographs of two different cells. a) Cell with patterned GDL and b) cell with commercial GDL. Anisotropic scale. Cathode is shown on top and anode on the bottom. The cell is operated in counter flow, the cathode inlet and anode outlet are at the left side. For water quantification purposes the 0 is set at the beginning of the active area from the left. Operating conditions: stoichiometry $y_{\text {Cathode }} 1.4, i=1.5 \mathrm{~A} / \mathrm{cm}^{2}$, radiographies during the last 10 minutes of the each experiment.

increasing, predictably for the commercial sample during the drying period. The HFR for the cell with the patterned sample is $10 \mathrm{~m} \Omega \cdot \mathrm{cm}^{2}$ higher, which is not a significant difference.

Liquid water distribution.-To get a better understanding of the cells behavior, the liquid water distribution images were analyzed for 4 different key periods:

- beginning of operation (from $\mathrm{t}=0$ to $\mathrm{t}=10 \mathrm{~min}$ )

- before the first voltage drop for the commercial cell (from $\mathrm{t}=25 \mathrm{~min}$ to $\mathrm{t}=35 \mathrm{~min}$ )

- stable operation (from $t=52 \mathrm{~min}$ to $t=62 \mathrm{~min}$ ),

- end of experiment (from $\mathrm{t}=66 \mathrm{~min}$ to $\mathrm{t}=76 \mathrm{~min}$ ).

The images were averaged over the mentioned 10 minutes periods. Figure 5 shows the images for the end of experiment, the other 3 sets of images can be found in the supplementary information (Figure S2 from the cell with patterned sample and Figures S3 for the cell with commercial sample).

For the cell with the patterned sample, there is only little water accumulating in the channels of the cathode flow field (Figures 5a and S2). Looking at the cathode GDL water distribution, the effect of the patterned wettability can be seen even at this stage, with the periodic pattern of water accumulation corresponding to the hydrophilic regions. Compared to the commercial sample (Figures 5b and S3) the patterned GDL has a higher water saturation, even in the hydrophobic regions. Since the cell was operated in counter flow, the GDLs at the extremities of the cell are drier at the beginning of operation (Figure S2a), but this distribution evens out after 30 minutes (Figure S2b). An important point to note is that, while the patterned GDL accumulates more water, the cathode flow field of the corresponding cell never exhibits channel clogging due to water. The situation is very different for the cell with the commercial GDL sample. For this cell, the GDL water content is generally low, but the water accumulation in the flow field channels on the cathode side is much higher than with the patterned sample.

The anode outlet has a large increase in water content but, most remarkably, cathode channels are filled with water over two thirds of the channel length already after 30 minutes of operation (Figure $\mathrm{S} 3 \mathrm{~b}$ ). The cathode flow field has 6 dead-ended inlet channels of $1 \mathrm{~mm}$ width each (Figure 1b). Over a large portion of the channels length, the water content is near the quantification limit of $6.6 \mathrm{~mm}$. Due to the low transmission, the precise number of blocked channels cannot be determined, but the measured water thickness indicates that, probably, all 6 input channels are clogged with water. The comparison of this measurements with data obtained by neutron imaging in a through plane configuration (See video 1 in the Supplementary Information) confirms that the water observed in the cathode channel is mostly located in the cathode inlet channels.

Water tends to accumulate in the inlet channels because the pressure drop generated by the interdigitated flow field is not sufficient to break through the hydrophobic GDL. Studies on water imbibition of GDL set the water breakthrough capillary pressure of a hydrophobic GDL to be approximately $40 \mathrm{mbar}^{21-23}$ which is in the range of the pressure drop measured at minute 35 . The convective transport through the GDL then concentrates in the cathode inlet side, causing of the rise of $\Delta \mathrm{P}_{\mathrm{Ca}}^{\mathrm{r}}$. In the area where the inlet channels are blocked, the transport of oxygen to the catalyst layer only occurs by diffusion from the outlet channels, resulting in increased mass transport losses and in the cell voltage drop.

After the drying period of the commercial cell, the water content for the GDL increases again slightly in the anode inlet region, meanwhile the water content on the anode channel decreases (Figure S3c). The absolute difference in the water content of the cathode channel cannot be evaluated due to the low transmission signal, but, again, two thirds of the cathode channel region have water above our quantification threshold. At the end of the experiment (Figure 5b), the water distribution is similar to what is observed during the stable time after the drying period, and the water responsible for the final pressure drop increase and cell failure cannot be clearly identified. Overall, we can clearly correlate the much higher water content in the cathode channels of the cell with a commercial GDL to the increased pressure drop and lower performance.

In Figure 6, a magnified section of the images obtained at the end of the experiment is shown. For the cell with the patterned GDL, the water accumulates in accordance to the periodic pattern on the cathode side, both in the GDL and in the channels. The hydrophilic areas of the GDL lower the capillary pressure necessary for the water to permeate through the GDL, acting as water ejection regions and form a bypass between the inlet and the outlet channels, as expected. The 
a)
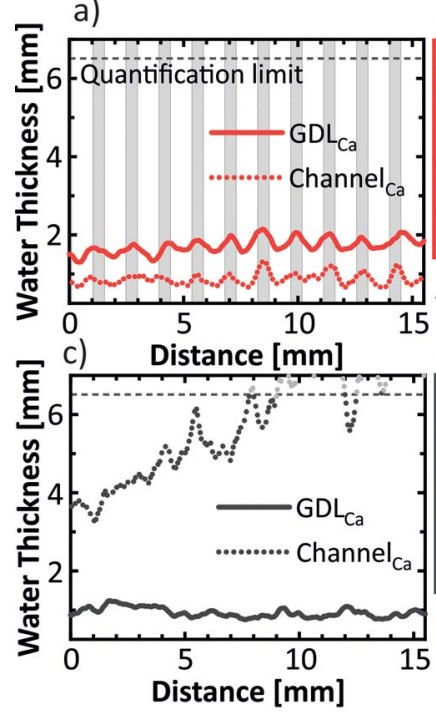

b) Patterned

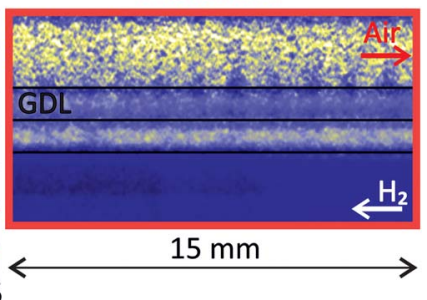

d) Commercial

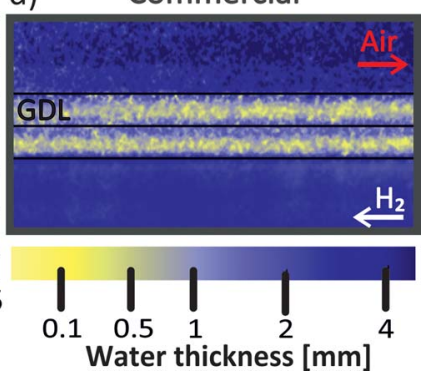

Figure 6. Detail of water distribution for a $15 \mathrm{~mm}$ long section starting at $11 \mathrm{~mm}$ from the 0 set in Figure 5. a) Cathode water profile and b) neutron radiograph of the cell with patterned GDL. c) Cathode water profile and d) neutron radiograph of the cell with commercial GDL. Operating conditions: stoichiometry Cathode $1.4, i=1.5 \mathrm{~A} / \mathrm{cm}^{2}$, radiograph at the end of the experiment.

water content in the GDL is higher than for the commercial sample, not only in the hydrophilic areas but also in the hydrophobic areas and even in the anode GDL. This issue will be further discussed later.

Impact of operating conditions.-For the rest of the conditions analyzed, the current density steps were hold only for shorter periods due to limitations of the experimental time at the beamline. Figure 7 shows the voltage and pressure drop average values after 30 minutes of operation. If the voltage of the cell was below $0.2 \mathrm{~V}$ at any moment before 30 minutes, no data point is shown. For all the tested conditions, after 30 minutes of operation, the voltage for the cell with patterned GDL is higher than for the cell with commercial GDL.

Regarding the cathode pressure drop, higher values are seen at stoichiometry 1.4 (Figure 7b), because the gas flow is not high enough to remove accumulated water efficiently. For the commercial sample, the only point where the cell does not flood is at the lowest current step.

The pressure drop for the commercial cell operated at stoichiometry of 1.6 (Figure 7d) show the expected behavior after 30 minutes of operation. The higher the current density is, the more water is produced and accumulated and therefore, the higher the pressure drop increase in the cathode rises. Nevertheless, after 60 minutes of operation, the cell does not show a trend anymore. This lack of trend can be related to the instability of the water accumulation in interdigitated flow fields. Further insight is given by observing the temporal evolution of the pressure drop (Figures S4-S7). At $1.0 \mathrm{~A} / \mathrm{cm}^{2}$ (Figure S5c-d), the pressure drop increase is relatively low during the first 30 minutes of operation, after which a significant increase is observed. On the contrary, when operating the cell at $1.5 \mathrm{~A} / \mathrm{cm}^{2}$ (S6c-d) the pressure drop is stable during the first 55 minutes of operation, and an increase is only seen during the last 5 minutes. Finally, at $2.0 \mathrm{~A} / \mathrm{cm}^{2}$ (S7c-d) $\Delta \mathrm{P}_{\mathrm{Ca}}^{\mathrm{r}}$ exhibits a first slight increase after 40 minutes of operation and after a short stable period, it starts increasing during the last 5 minutes. These unpredictable differences illustrate the stochastic aspect of the water accumulation and the corresponding pressure drop increase. In contrast to what is observed with the cell using a commercial GDL, the cell with patterned wettability GDL shows a stable performance for all tested conditions.

For the cell with patterned GDL, a slight increase of cell voltage is observed when increasing the stoichiometry. Opposite to this, no clear conclusion can be drawn from performance differences at different stoichiometries for the cell with a commercial GDL. For example, comparing the water distribution at $1.0 \mathrm{~A} / \mathrm{cm}^{2}$ for $\mathrm{t}=20 \mathrm{~min}$ to
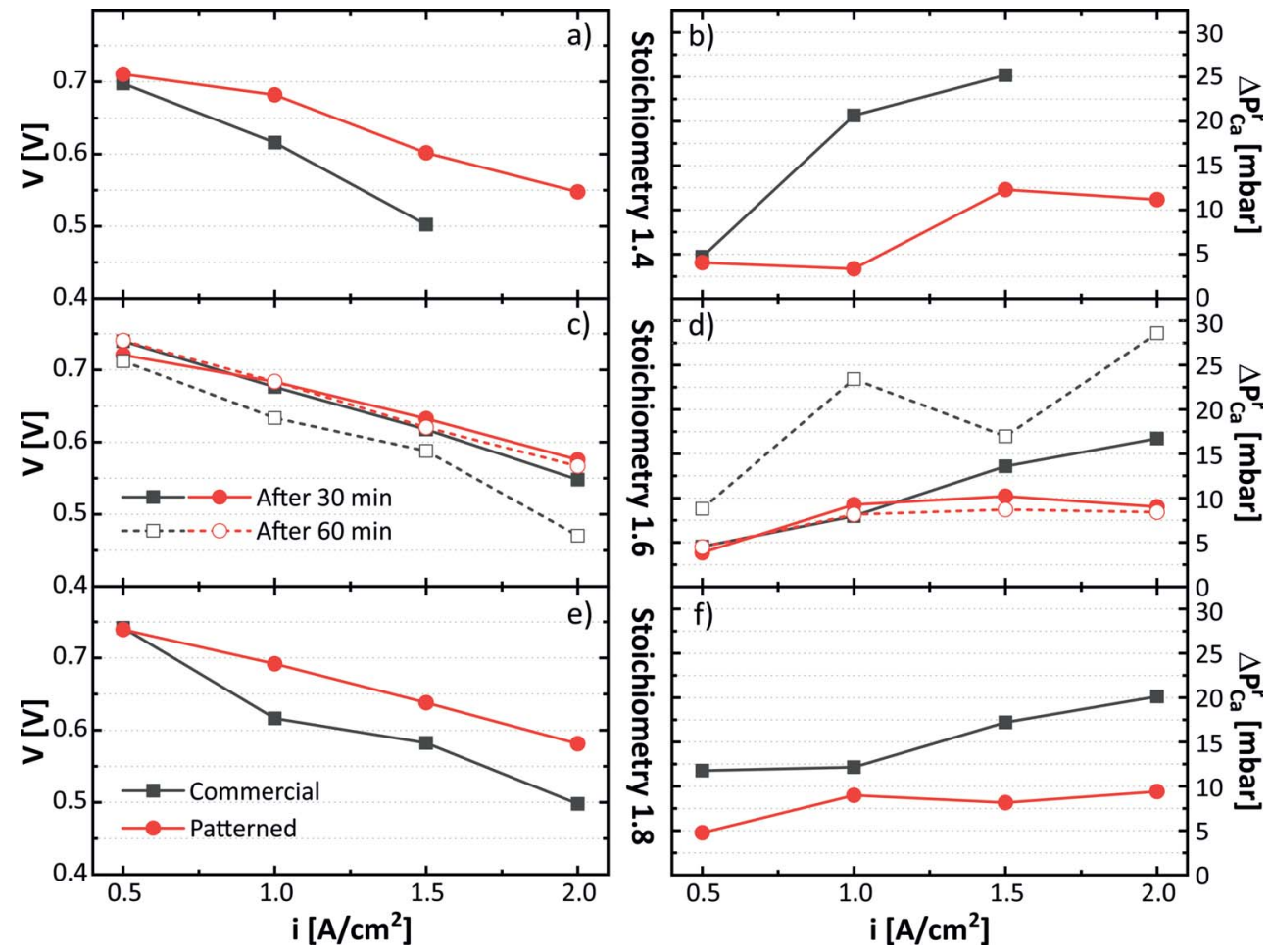

Figure 7. Long term performances of two different cells; commercial GDL (gray squares) and patterned GDL (red circles). On the left the polarization curve for each stoichiometry and on the right the cathode pressure drop is shown. a) and b) correspond to a cathode stoichiometry of 1.4, c) and d) stoichiometry of 1.6 and e) and f) stoichiometry of 1.8. Data acquired after 30 minutes of operation. c) and d) the dotted lines corresponds to data acquired after 60 minutes. 


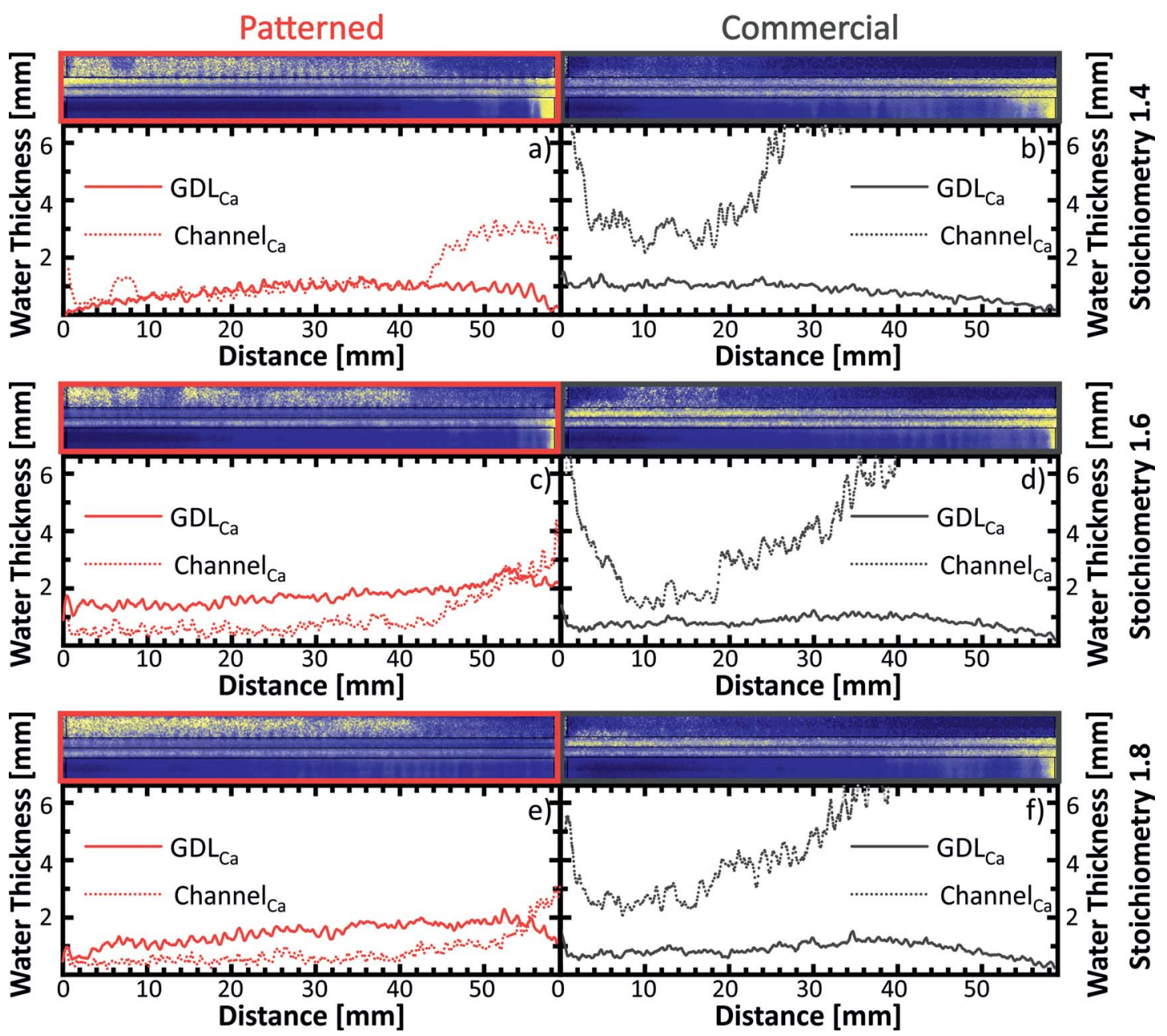

Figure 8. Water distribution for different stoichiometries. a) and b) correspond to a cathode stoichiometry of 1.4 , c) and d) stoichiometry of 1.6 and e) and f) stoichiometry of 1.8. Cathode GDL and channel water profile and neutron radiograph of the cell with patterned GDL (left) and commercial GDL (right). Operating conditions: $i=1.0 \mathrm{~A} / \mathrm{cm}^{2}, 30$ minutes operation.

$\mathrm{t}=30 \mathrm{~min}$ (Figure $8 \mathrm{~b}-8 \mathrm{f}$ ) for the cell with the commercial sample, there is a higher water content in the channels when testing the cell with a stoichiometry of 1.4 but there is not much differences for higher stoichiometries. It was expected that operating at higher stoichiometry would prevent the increase of pressure drop, since using a higher gas flow helps removing water from the GDL, which should lead to higher performances. It was also expected that the use of different stoichiometries would have a higher impact on the commercial sample since water accumulation is more severe for this GDL. These statements are true for the lowest stoichiometry; using a stoichiometry of 1.4 results in higher water content in the channels, higher pressure drop increase and lower voltages, but for stoichiometries of 1.6 and 1.8, no clear trend can be observed (Figure S4-S7). Again, the stochastic aspect of water accumulation in the cell with commercial GDL can be held responsible for this lack of trend. Nevertheless, it can be concluded that the patterned sample is less influenced by the gas flow stoichiometry (Figures 7 and $8 \mathrm{a}-8 \mathrm{e}$ ), and has a consistent performance and pressure drop between all used conditions, due to the better water management and lower water accumulation in the flow field channels. These differences in performance and water distribution have not been matched by the cell with the commercial sample when changing the conditions toward conditions more favourable to prevent water accumulation and improved water management (Figures 7 and 8).

Performance in the first minutes of operation.-An interesting point to note is that the voltage for the cell with commercial GDL is higher than for the sample with patterned GDL in the very begin- ning of operation (see Figure 4). After a few minutes of operation, the performance of the commercial cell starts dropping as $\Delta \mathrm{P}_{\mathrm{Ca}}^{\mathrm{r}}$ rises and more water accumulates in the cathode inlet channels. This behavior is seen in most measured conditions (see Figures S4-S7), and the comparison of initial performances is summarized in Figure S8. Only for the last experiment (stoichiometry of 1.8), the initial performances are similar for both cells. A possible explanation is that the testing conditions were very harsh for the cell with commercial GDL, including flooding of a large portion of the active area, resulting in cell damage over the duration of the test. To explain the higher initial performance of the cell with the commercial sample, we must consider that, as mentioned previously, a significantly higher amount of water accumulates in the GDL with patterned wettability - even in the hydrophobic zones. We assume that, due to the lateral water transport in the GDL, the hydrophobic areas are not wide enough to remain free of water. Therefore, it is possible that with an optimized pattern (e.g. more separation between the hydrophilic lines), a lower overall GDL water content and a higher performance could be achieved, while keeping the stability demonstrated here due to the prevention of water accumulation in the gas flow channels.

Towards interdigitated flow fields in stack configuration.-As previously mentioned, the performance instability shown by the commercial sample (Figure 4) is very common for a cell with an interdigitated flow field and it is the main reason why this type of flow field have not been used so far in a commercial fuel cell stack. ${ }^{11}$ In a stack, the cells are packed one after the other; the gas is distributed through a 
common manifold in parallel to all the individual cell inlets. If all cells have the same pressure drop, the gas is distributed equally throughout the whole stack and all cells have the same gas flow. From the electrical point of view, all cells are connected in series so the current is evenly drawn through all cells and in theory if all cells have the same characteristics, activation losses, ohmic losses and mass transport losses, then voltage will be similar.

Due to the stochastic aspect of water accumulation mentioned previously, the pressure drop will start to increase at a different time in each cell. The gas will preferentially go through the paths with lower pressures drops, resulting in a lower gas flow in the cells with higher water accumulation. In turn, the lower gas flow means that water is less efficiently removed and will further accumulate, resulting in a deadly spiral. As current keeps being drawn due to the series connection of the cells, the stoichiometry is reduced until starvation is reached. Besides the unreliable operation due to the induced cell shutdown, starvation can severely damage the cell. In particular, the lack of $\mathrm{H}_{2}$ on the anode side, triggers carbon corrosion. ${ }^{24}$ Therefore, a fuel cell design that is prone to water accumulation and has unpredictable pressure drops cannot be used in a stack configuration. We expect this issue to be solved by the use of our GDL with optimized water management. As previously stated, the cell using this GDL has a lower pressure drop, but more remarkably, this pressure drop is stable. Since interdigitated flow field mitigate the mass transport losses these stacks will theoretically reach higher power densities compared to stacks with conventional flow field designs.

\section{Conclusions}

We have demonstrated that, using a GDL with patterned wettability, the stability and performance of a cell using an interdigitated flow field is significantly improved. Using neutron imaging, we have shown that this better performance is related to a much lower accumulation of water in the inlet channels of the flow field. Even at conditions with very low gas velocities and high current density, where water is prone to accumulate in cells, the GDL with patterned wettability effectively acts as a water by-pass, preventing water accumulations and minimizing the pressure drop. The hydrophilic regions in the GDL provide a path with lower capillary pressure, which prevents water accumulation in the inlet channels, and the corresponding pressure drop variations, eventually stabilizing the cell performance.

Opposite to what is seen in the gas flow channels, the GDL with patterned wettability exhibits a higher water accumulation than the commercial GDL. This does not seem to be detrimental to the stability, although the higher performance of the cell with commercial sample in the very first minutes of operation indicates that there is still potential for improvement using optimized wettability patterns to reduce the GDL water saturation.

Besides being lower, the pressure drop is also much more stable when using our GDL featuring patterned wettability. We expect that this striking feature will allow the use of interdigitated flow fields in a stack configuration in the future - a possibility that has been excluded so far due to the severe cell-to-cell misdistribution of gas flows related to unpredictable water accumulation.

\section{Acknowledgments}

The authors gratefully acknowledge the funding from the Swiss National Science Foundation (SNSF, project no. 172474) as well as the Swiss Competence Centre for Energy Research Efficient Technologies and Systems for Mobility (SCCER Mobility). They further acknowledge Pia Klee for her assistance with sample preparation and during the performance of beam time experiments, Elias Rehmann for technical support at Brugg FHNW and Dirk Scheuble for the design and manufacturing of the interdigitated flow fields and of the cell test fixture.

\section{ORCID}

Victoria Manzi-Orezzoli (D https://orcid.org/0000-0002-0998-0792

Muriel Siegwart (1) https://orcid.org/0000-0002-5374-1473

Thomas J. Schmidt (1) https://orcid.org/0000-0002-1636-367X

Pierre Boillat (iD https://orcid.org/0000-0002-5683-8086

\section{References}

1. M. F. Mathias, J. Roth, J. Fleming, and W. Lehnert, Handb. Fuel Cells, 3, 517 (2010).

2. F. N. Büchi and P. Boillat, in Encyclopedia of Applied Electrochemistry, G. Kreysa, K. Ota, and R. F. Savinell, Editors, p. 1661, Springer New York, New York, NY (2014).

3. K. Tajiri, J. Karani, and U. N. Shrivastava, J. Electrochem. Soc., 165, F1385 (2018).

4. D. Spernjak, A. K. Prasad, and S. G. Advani, J. Power Sources, 195, 3553 (2010).

5. G. Zhang, L. Guo, B. Ma, and H. Liu, J. Power Sources, 188, 213 (2009).

6. S. Luo and H. Liu, Int. J. Hydrogen Energy, 39, 9440 (2014).

7. T. Van Nguyen, J. Electrochem. Soc., 143, L103 (1996).

8. W. He, G. Lin, and T. Van Nguyen, AIChE J., 49, 3221 (2003).

9. J. P. Owejan, T. A. Trabold, D. L. Jacobson, D. R. Baker, D. S. Hussey, and M. Arif, Int. J. Heat Mass Transf., 49, 4721 (2006).

10. X. Wang and T. Van Nguyen, J. Power Sources, 197, 50 (2012)

11. T. Van Nguyen and M. W. Knobbe, J. Power Sources, 114, 70 (2003).

12. N. J. Cooper, A. D. Santamaria, M. K. Becton, and J. W. Park, Energy Convers. Manag., 136, 307 (2017).

13. A. Forner-Cuenca, V. Manzi-Orezzoli, J. Biesdorf, M. El Kazzi, D. Streich, L. Gubler, T. J. Schmidt, P. Boillat, and M. El Kazzi, J. Electrochem. Soc., 163, F788 (2016)

14. A. Forner-Cuenca, J. Biesdorf, V. Manzi-Orezzoli, L. Gubler, T. J. Schmidt, and P. Boillat, J. Electrochem. Soc., 163, F1389 (2016).

15. A. Forner-Cuenca, J. Biesdorf, L. Gubler, P. M. Kristiansen, T. J. Schmidt, and P. Boillat, Adv. Mater, 27, 6317 (2015).

16. M. Cochet, A. Forner-Cuenca, V. Manzi-Orezzoli, M. Siegwart, D. Scheuble, and P. Boillat, Fuel Cells, 18, 619 (2018).

17. E. H. Lehmann, P. Vontobel, and L. Wiezel, Nondestruct. Test. Eval., 16, 191 (2001).

18. P. Boillat, G. Frei, E. H. Lehmann, G. G. Scherer, and A. Wokaun, Electrochem. Solid-State Lett., 13, B25 (2010).

19. P. Boillat and ETH thesis, (2009).

20. P. Boillat, C. Carminati, F. Schmid, C. Grünzweig, J. Hovind, A. P. Kaestner, D. Mannes, M. Morgano, M. Siegwart, P. Trtik, P. Vontobel, and E. H. Lehmann, Opt. Express, 26, 15769 (2018).

21. J. T. Gostick, M. A. Ioannidis, M. W. Fowler, and M. D. Pritzker, J. Power Sources, 194, 433 (2009).

22. J. D. Fairweather, P. Cheung, J. St-Pierre, and D. T. Schwartz, Electrochem. Commun., 9, 2340 (2007).

23. A. Forner-Cuenca, J. Biesdorf, A. Lamibrac, V. Manzi-Orezzoli, F. N. Büchi, L. Gubler, T. J. Schmidt, and P. Boillat, J. Electrochem. Soc., 163, F1038 (2016).

24. N. Yousfi-Steiner, P. Moçotéguy, D. Candusso, and D. Hissel, J. Power Sources, 194, 130 (2009). 